\title{
The Labor Market Participation of Sandwich Generation Italian Women
}

\author{
Laura Pagani · Anna Marenzi
}

Published online: 23 May 2008

(C) Springer Science+Business Media, LLC 2008

\begin{abstract}
We empirically analyzed the labor market participation of Italian women, with special emphasis on the role of intergenerational family links. Older relatives, on the one hand, discourage the work participation of women by requiring care; on the other hand they may provide household services favoring labor supply. We studied this dual impact estimating a trivariate probit model where the three choices to be in the labor force, to use informal help from older relatives and to care for them are jointly determined. Our estimates show that care duties towards members of the previous generation hinder the labor market participation of Italian women, and that informal help received from older relatives strongly increases their probability of being engaged in paid work.
\end{abstract}

Keywords Female labor supply $\cdot$ Intergenerational links

The standard model of labor supply is based on the study of the time allocation decision of an individual between work and leisure, the latter being generally intended as time not devoted to activities in the market. However, household production theory (Becker 1965) underlines that the choice actually regards the allocation of time between work in the market, household work and leisure. This extension of the standard model proves to be

A previous version of this paper was presented at the Centre for Household, Income, Labor and Demographic Economics, Turin, Italy, the Italian Association of Public Economics conference, Pavia, Italy, and the 2004 European Low-wage Employment Research network annual conference, London School of Economics, London. We are grateful to all participants and, in particular, to Lorenzo Cappellari and Marco Leonardi for valuable comments. We also thank two anonymous referees for valuable suggestions.

\section{Pagani $(\bowtie)$}

Dipartimento di Economia Politica, Università di Milano Bicocca,

Piazza dell'Ateneo Nuovo 1, 20135 Milan, Italy

e-mail: laura.pagani@unimib.it

A. Marenzi

Università dell'Insubria, Via Monte Generoso 71, 21100 Varese, Italy

e-mail: anna.marenzi@uninsubria.it 
especially useful in studying female labor supply, given the traditional division of roles within the family: The time that women do not spend on the market is mainly devoted to caring for family members and to household chores that, although unpaid, turn out to be productive.

The empirical literature regarding female labor supply, based on the model of the threeway choice-work for the market, household work and leisure-has shown how the presence of children, especially of pre-school age, reduces the amount of time spent on the market in favor of time devoted to caring for family members (see, for example, Browning 1992; Hill et al. 2004; Nakamura and Nakamura 1992). In addition, the rapid aging of the population in most western countries has, in the last decades, led the studies concerning female labor supply to consider the effect of the need to care for older people (Chang and White-Means 1995; Ettner 1995, 1996; Kolodinsky and Shirey 2000; Wolf and Soldo 1994). In this regard, Ettner (1995) noticed that, although the decision to care for a senior person and for a child differ in many aspects, the influence of the commitment to care for older people can be studied similarly to the commitment toward children. Thus, the responsibility toward older people may compound the obligation toward children, and this has led to the definition of the term sandwich generation referring to women who have to provide care and support both to the preceding and to the following generations.

Obviously, in the case that the need to care for older relatives is combined with care responsibilities towards children, a stronger discouraging effect on labor supply is produced. This is a very important issue, as in most western countries the percentage of old people in the total population is rising strongly and continuously due to reduced fertility rates and to longer average life expectancy, and this fact signifies that the need to care for older people is destined to increase as well (see, for example, Meeks et al. 1999).

However, an issue relative to family links, so far largely overlooked by current economic literature, is that cross-generational ties may also work in the opposite direction, as in some cases women may receive help from members of the preceding generation in carrying out household chores and in caring for their family members. Support from seniors reduces the household productivity of women and this, according to the household production model, favors female labor market participation. Therefore, ties with the original family produce two opposing effects on women's labor supply: on the one hand they reduce it if there is a senior person in need of care; on the other hand they increase it if the senior person can provide help in household and care activities.

Italy represents a very interesting country to study in the above respect, as original family ties remain generally very strong throughout life. This circumstance results in a cross-generational pact; parents help their adult children even when they have formed an independent family and, in exchange, get assistance and care if needed. Thus often working women, even after leaving their original family unit, can count on the support of older relatives, such as parents and parents-in-law, and frequently they, in turn, will care for them when needed: Various studies have shown that the care duties toward elderly relatives are more often accomplished by women than by men (Caputo 2002; Ettner 1995; Koh and MacDonald 2006; Lai and Leonenko 2007; Nichols and Junk 1997).

In light of these considerations, and using as a reference the model of household production, the objective of this research was to evaluate the two opposing impacts of older relatives on Italian women's labor market participation. For this purpose, we used the information contained in the special section of the Bank of Italy's Survey of Household Income and Wealth (SHIW) for the year 2000 (Banca d'Italia 2002) Unpaid Labor and Services to the Family which allows, for the first time in Italy, the separation of the two effects produced by older people on female participation. 
The remainder of the paper is organized as follows. In section "Family Ties and Participation" we describe the conceptual model we used as a guide for estimation and we present a brief survey of the literature; section "Econometric Strategy" explains the econometric strategy; section "Data and Descriptive Analysis" provides a description of the data and reports some descriptive analysis; section "Regression Results" contains a discussion of the main results; section "Conclusion" briefly summarizes and concludes.

\section{Family Ties and Participation}

The effect of family and cross-generational ties on optimal time allocation can be understood on the basis of the household production theory (Becker 1965). According to this model, utility of individuals depends on total amount of goods and services purchased in the market, total amount of home produced goods and services, and leisure. Household production is based on a decreasing return production function in which time is one of the inputs; total time available to individuals is divided between household work and market work, which do not bring utility, and leisure.

The woman's caregiving responsibilities toward family members contribute in defining her household productivity. An increase in such responsibilities, for instance, due to the needs of children compounded by those of older parents, determines a rise in the woman's household productivity due to increased opportunities for joint production and to economies of size (Bryant 1990); this productivity rise modifies the woman's optimal allocation of time. First of all this happens because household work becomes more productive and a production substitution effect is created, whereby the woman substitutes household work for work in the market. Secondly, the increase in productivity determines an income effect, which raises demand for leisure and subsequently reduces female labor supply even more. Thus, according to the model of household production, an increase in care responsibilities reduces the amount of time spent on the labor market.

Senior relatives may provide assistance to women in carrying out household chores. In this case household productivity decreases and, as a result, women will tend to substitute work in the market for household work. In addition, the reduction in real income due to the decreased household productivity leads to a decrease in the demand for leisure, favoring participation. Thus, the ties with preceding generations may also have the opposite effect on labor supply. Indeed, research has shown that older relatives receive in-kind services in exchange for childcare services (Koh and MacDonald 2006; Presser 1989), and, thus, woman's household productivity simultaneously rises because of the care provided and decreases because of the help received. The net impact of these productivity changes depends on which of the two effects prevails.

With regard to the care provided to older people, existing studies, mainly based on U.S. data, have not univocally proven its effect on female labor supply. Wolf and Soldo (1994), estimating simultaneously the choice of employment and care supply on a sample of married women, did not find a decrease in the propensity to work for women who assisted co-residing senior relatives. Ettner (1995), taking into account the possible endogeneity of care activities, showed that co-residing with a disabled senior person has a relevant discouraging effect on participation in the labor market, while such effect is lessened if the senior does not live within the family nucleus. In a subsequent analysis, Ettner (1996) found that the negative impact is higher for women than for men. Chang and White-Means (1995) showed that the discouraging effect is particularly strong for less educated women co-residing with the senior person. Kolodinsky and Shirey (2000) tested whether the effect 
of the presence and characteristics of older parents on women's labor supply differs according to the fact that they reside or not within the family nucleus. They found that co-residing increases the probability of participation, even if such a probability decreases as the parent grew older (age can be interpreted as an indicator of health). The authors also checked whether the woman's characteristics has a different impact on the probability of participation, depending on the parent being a co-resident or not. The results showed that if the senior person co-resides with the family, as the woman's age increases, so does the discouraging effect on participation. Koh and MacDonald (2006) found a negative correlation between employment and time-help to parents, although they did not control for potential endogeneity in the employment-caregiving relationship.

The influence of the preceding generation's support on female labor supply has hardly been treated explicitly in the economic literature. Hunts and Avery (1998) studied the amount and timing of child care services offered by relatives on a sample of U.S. families. Their results suggest that extended household support systems play an important role in the labor force participation of mothers, especially when they work a large proportion of nontraditional work hours; however, as they stated, the possibility of reverse causality between participation and receipt of child care from relatives should be better investigated. Some indications regarding the link between help from relatives and labor participation can be gained from some studies dealing with the relationship between female participation and the offer of formal child care services; such studies have checked, in different ways, for the availability of support provided by the enlarged family. Their results generally show that if the woman can count on the availability of senior parents, then her probability of participating increases. Ribar (1992) measured the availability of informal child care services using the number of adults living in the family nucleus; the variable has a positive effect on participation. With specific reference to Italy, Chiuri (2000) assumed that the family can count on the help of the preceding generation if at least one member of the couple resides in the province where he/she was born, and noticed a positive effect on woman's labor supply. Del Boca (2002) employed the fact that at least one of the mother's parents was alive as a proxy for the help of the extended family and found a positive effect of this variable on participation. Bratti (2003) showed similar results measuring the availability of support from relatives combining the two hypotheses made by Chiuri (2000) and Del Boca (2002). However, in these studies the mere presence of a senior parent is considered equivalent to the availability of his/her help to the family. This hypothesis overlooks the fact that the presence of older relatives does not necessarily mean they can help; indeed, it can be an additional burden for the woman if the older person needs care.

It is important to consider that the current empirical literature has not yet considered jointly the two-fold impact of older relatives on women's probability of being part of the labor force. This research aims to fill this gap.

\section{Econometric Strategy}

In this section we describe the model we used to empirically study the link between intergenerational ties and female participation and to distinguish the two opposing effects of older relatives on it. In estimating the participation equation an important econometric issue had to be taken into account. More specifically, we had to deal with the potential endogeneity of the help received and care provided variables.

A simple way to assess the impact on labor market participation of help received and care provided is by means of a probit model where participation is the dependent variable. 
However, the causal relationship between participation and the choice to care for older relatives on the one hand and between participation and the choice to use help from relatives on the other hand is not clear-cut. For example, the probability of using help may be higher for participating women and, thus, the coefficient of the demand for help variable in a probit equation where participation is the dependent variable is clearly biased, as it overstates the positive impact of relatives' help on labor market participation; in other words, after probit estimation we could not infer that women increase their labor supply as a result of family help. Similarly, if being in the labor force hinders providing care to senior relatives, the coefficient of the care provision variable in a probit equation where participation is the dependent variable is clearly biased, as it overstates the negative impact of care provision on labor market participation.

Thus, both the care provided and the help received variables must be treated as potentially endogenous variables in our model. In order to take this potential source of endogeneity into account, we applied full information techniques estimating the three equations (i.e., participation, care provided and help received) simultaneously, because two-step techniques may be biased when the variable of interest, which in our case is the choice to participate in the labor market, is discrete (O'Higgins 1994).

Hence, our estimation strategy consisted of estimating a three equation latent dependent-variable model: We assumed that there are three underlying latent propensity variables $P^{*}, H^{*}$ and $C^{*}$, which represent, respectively, (a) propensity to participate, (b) propensity to use informal help, and (c) propensity to provide help to older relatives. These latent variables are not observable, but we observed the realized participation, help received and care provided. The propensities $P^{*}, H^{*}$ and $C^{*}$ may be mapped to three observable binary discrete variables $P, H$ and $C$ indicating whether or not the woman participated, used help or provided care to older relatives.

More precisely, these dummy variables are:

$$
P=\left\{\begin{array}{c}
1 \text { if } P^{*}>0 \\
0 \text { if } P^{*} \leq 0
\end{array} \quad H=\left\{\begin{array}{c}
1 \text { if } H^{*}>0 \\
0 \text { if } H^{*} \leq 0
\end{array} \quad C=\left\{\begin{array}{c}
1 \text { if } C^{*}>0 \\
0 \text { if } C^{*} \leq 0
\end{array}\right.\right.\right.
$$

The estimated model is a trivariate probit which allows the unobservables of the three equations to be jointly distributed as a trivariate normal with free correlations, and thus the model accounts for the possibility that some unobserved factors influencing participation also influence the choice both to use informal help and to provide care. The hypothesis of correlation between the unobserved components of the three equations can be tested after estimation by considering the joint significance of the coefficients of correlation between their error terms. To be more precise, in the trivariate probit model the error terms in the three equations are jointly distributed with a trivariate normal distribution function, that is $\left(\varepsilon_{P}, \varepsilon_{H}, \varepsilon_{C}\right) \sim \operatorname{MVN}(0, \Sigma)$ where $\Sigma$ is the variance-covariance matrix which has values of 1 on the leading diagonal while the off-diagonal elements are to be estimated. Thus, the matrix $\Sigma$ is given by:

$$
\Sigma=\left[\begin{array}{ccc}
1 & \rho_{P H} & \rho_{P C} \\
\rho_{H P} & 1 & \rho_{H C} \\
\rho_{C P} & \rho_{C H} & 1
\end{array}\right]
$$

where $\rho_{i j}$ is the correlation coefficient between $\varepsilon_{i}$ and $\varepsilon_{j}$, with $i, j=P, H, C$ and $i \neq j$. The fact that the off-diagonal elements of $\Sigma$ are potentially different from zero allows that unobserved characteristics influence two choices at the same time. 
Recapitulating, our model estimates simultaneously a structural participation equation with two endogenous dummies (help received and care provided variables) and two reduced form equations for the endogenous dummies.

Notice, however, that if we include these dummies in the participation equation, the equations for the endogenous dummies $H$ and $C$ require exclusion restrictions; more precisely, we need variables which influence $H^{*}$ and $C^{*}$ but which do not influence participation after help received and care provided have been controlled for. In this way, we pick the variation in help received and in care provided which is not correlated with the variation in participation propensity, and by means of this exogenous variation we can estimate the relationship between participation and $\mathrm{H} / \mathrm{C}$ eliminating the spurious correlation which is due to endogeneity.

The estimated model is the following:

$$
\left\{\begin{array}{r}
\operatorname{Pr}(P=1)=\beta_{P}^{\prime} X+\gamma_{P}^{\prime} H+\delta_{P}^{\prime} C+\varepsilon_{P} \\
\operatorname{Pr}(H=1)=\beta_{H}^{\prime} X+\alpha_{H}^{\prime} Z_{1}+\varepsilon_{H} \\
\operatorname{Pr}(C=1)=\beta_{C}^{\prime} X+\theta_{C}^{\prime} Z_{2}+\varepsilon_{C}
\end{array}\right.
$$

where $X$ is a vector of explanatory variables for participation, $Z_{1}$ is the instrument for $H$ and $Z_{2}$ is a vector including two instruments for $C$. The model was estimated using the simulated maximum likelihood method. ${ }^{1}$

As an instrument for the help received, we used the dimension of the city of residence, as living in smaller towns (less than 50,000 inhabitants) should make the use of family support provided by relatives easier, but it should not influence the probability to participate in the labor market. We used two instruments in the care provided equation. These are the age of the oldest relative among parents and parents-in-law and the number of sisters the woman has. The former instrument is a proxy for the health status of older relatives (Kolodinsky and Shirey 2000 used age as a proxy for declining functionality) and thus it should influence the probability of caregiving; as to the latter instrument, various studies (Caputo 2002; Ettner 1995; Nichols and Junk 1997) emphasized that care to older relatives is generally provided by daughters, who usually spread care-work evenly among themselves. For this reason, we expect that as the number of sisters of the woman increases, her probability of caregiving decreases. Both the age of the oldest relative and the number of sisters should produce no effect on the choice to participate.

To evaluate the validity of instruments we used functional form as identifying restrictions; first we tested the null hypothesis of insignificance of the instruments in the participation equation (test 1 ) and then we tested the null hypothesis of insignificance of the instruments, respectively, in the help received and in the care provided equations (test 2).

\section{Data and Descriptive Analysis}

The empirical study was conducted on data taken from the Bank of Italy's 2000 Survey of Household Income and Wealth (SHIW). This data set, which contains survey data, is the main source of information regarding income and wealth of Italian families, their sociodemographic features and their position in the labor market. SHIW 2000 also contains the

\footnotetext{
1 The software used was Stata; the command was mvprobit (see Cappellari and Jenkins 2003), that uses the Geweke-Hajivassiliou-Keane (GHK) simulator to evaluate the M-dimensional normal integrals in the likelihood function. A description of GHK simulator is in Greene (2003).
} 
special section Unpaid Labor and Services to the Family, which reports a wealth of information about household work and care activities carried out by women and the support that they receive from relatives. This is extremely important information (never before available with specific reference to Italy) for the study of the relation between work choices and family ties. ${ }^{2}$

For purpose of estimation, we selected a sample of married or partnered mothers in the 19-64 age group who were heads of the family or the spouses/live-in partners of the head of the family. ${ }^{3}$ We excluded daughters, other relatives of the head of the family and other co-residing women, as for them family responsibilities are usually lower. Students and retired women were not included in the sample. Last, according to the indications of Del Boca (2002), to isolate women who can potentially count on the support of a senior person, we eliminated those who do not have at least one living parent or parent-in-law.

The participation dependent variable, $P$, is equal to 1 if the woman belongs to the labor force, that is was employed or unemployed. The status of unemployment was defined by the individual's answer to the question on the prevailing condition in the year and, thus, it does not correspond to the official definition; to partly correct this imprecision, we considered as not belonging to the work force those who stated they were unemployed or were first job seekers, but who had not actively searched for a job during the previous year. Obviously, even with this correction the number of individuals belonging to the labor force is overestimated since for an individual to be classified as unemployed she/he has to have actively sought a job in the last 30 days. Women whose stated main activity was homemaker and women asserting that they could afford not to work were not considered part of the work force; thus, for them the dependent variable takes the value of 0 .

The help received dependent variable, $H$, takes the value of 1 for women who employed the help of relatives for household or care duties. Notice that in the Bank of Italy survey the question about the help received from relatives is referred only to the support obtained from non-co-resident relatives. To consider also the help provided by co-residing older relatives, we assumed that women with a live-in relative aged over 60 who did not need care, received help from her/him. In other words, we supposed that if relatives aged over 60 live within the family nucleus and do not need care, they provide household and child care support.

Finally, the care provided dependent variable. $C$, takes the value of 1 for women who stated that they devoted time to caring for residing and/or non-co-residing older relatives. The variable was constructed using information contained in the SHIW 2000 special section. In particular, it takes the value of 1 for women who stated they dedicated time to caring for non-co-residing relatives, and for those co-residing with a senior above 60 years old different from the husband who affirmed to care for other (with respect to children up to 14 years old) residing family members. Both the variable $H$ (help received) and the variable $C$ (care provided) refer to weekly help.

\footnotetext{
${ }^{2}$ Despite the fact that the special section of SHIW 2000 contains important information regarding family links, our research would be further enhanced by other information, for example regarding attitudes about work on the part of the woman, her partner, or extended family. However, this kind of information could be gathered only through focused interviews, which would be problematic to conduct on a representative sample of the population under study.

3 Initially we chose the 15-64 age range because it corresponds to the working age. However, in our sample there were no married/partnered mothers labor force participants who were heads of family or spouses/livein partners of the head of the family younger than 19 . Thus, the age range of the women who were actually included in our analysis is 19-64.
} 
The explanatory variables of the participation equation, beginning with those intended to account for the influence of family responsibilities on participation, were divided into three groups:

1. Family links. In addition to the two endogenous dummy variables, $H$ and $C$, which should directly permit us to test the impact of intergenerational family links on participation, we included a set of dummy variables checking for the age of the youngest child (Chiuri 2000). We also inserted a variable measuring the availability within the region of residence of places for senior persons in public care facilities in order to verify whether or not public care services to older people act as a substitute for informal care provided by women to their parents and parents-in-law, thus favoring participation (data relative to public senior care services by region are available from the authors on request). This group of variables also included a variable measuring the number of places in public crèches available, on a regional level, every 100 children between 0 and 2 years old (data are available from the authors upon request). We did not insert a variable accounting for the offer of services to children aged 3-5 because in Italy the demand for such services is not rationed. Finally we entered in this group of variables the total net income of the husband/partner and its squared value in the reference year. The latter accounts for potential non-linearities in the relationship between participation and husband's income.

2. Human capital. Three dummy variables for the level of education-primary education, lower secondary education and upper secondary education-belong to this group. The excluded category is tertiary education (college degree, graduate and post-graduate degrees). Age and its square are included as a measure of potential work experience.

3. Family, cultural and economic background. According to the results obtained by Del Boca et al. (2000), we included two dummy variables taking the value of 1 in the cases, respectively, of mother and mother-in-law working at the present age of the interviewed woman. The idea is that a positive attitude toward female market work, as witnessed by a working mother and/or mother-in-law, should favor female participation. We entered also a dummy variable identifying women living in the south of Italy, where intergenerational family links and the role of the traditional family seem to be stronger than in the rest of the country. In addition, the Italian southern labor market performs considerably poorer than the rest of the country, as witnessed by the huge gap in unemployment rates between the South and the Centre-North (in 2003 $+12.1 \%$ with respect to the North and $+9.2 \%$ with respect to the Centre) and by the higher incidence of long term unemployment. These facts may contribute to a wider diffusion of the so-called discouraged worker effect: Southern women more often than other Italian women stop job seeking because they think finding a job is too difficult, and, thus, they exit the labor force. In order to distinguish the Southern cultural effect from the unemployment effect we introduced the regional rate of female unemployment among the regressors.

Descriptive statistics for the estimation sample, also separately between participating and non-participating women, are reported in Table 1. Differences between mean values and results of $t$ tests for the hypothesis of their equality are also shown in the Table. Participation is around $47 \%$ and almost 1 woman in 10 demands help from the previous generation; notice, however, that the percentage rose/fell to $16.2 \% / 4.1 \%$ for participating/ non-participating women. Almost 1 woman in 3 provides care to seniors, but the percentage is considerably higher $(+7.2$ percentage points) for non-participating women. In Italy the female education level is still very low: Only $9.3 \%$ of women have tertiary 
Table 1 Sample means

\begin{tabular}{|c|c|c|c|c|}
\hline & $\begin{array}{l}\text { All } \\
\text { women }\end{array}$ & $\begin{array}{l}\text { Participating } \\
\text { women }\end{array}$ & $\begin{array}{l}\text { Non-participating } \\
\text { women }\end{array}$ & $\begin{array}{l}\text { Mean } \\
\text { difference }\end{array}$ \\
\hline Participation rate & 47.3 & & & \\
\hline \multicolumn{5}{|l|}{ Family links } \\
\hline Help received & 0.098 & 0.162 & 0.041 & $-0.120 * *$ \\
\hline Care provided & 0.269 & 0.231 & 0.303 & $0.072 * *$ \\
\hline Youngest child $0-2$ years old & 0.128 & 0.127 & 0.129 & 0.002 \\
\hline Youngest child 3-5 years old & 0.126 & 0.138 & 0.115 & -0.023 \\
\hline $\begin{array}{l}\text { Youngest child 6-10 years } \\
\text { old }\end{array}$ & 0.201 & 0.228 & 0.177 & $-0.051^{*}$ \\
\hline $\begin{array}{l}\text { Youngest child 11-14 years } \\
\text { old }\end{array}$ & 0.136 & 0.160 & 0.115 & $-0.045^{*}$ \\
\hline Youngest child over 14 & 0.409 & 0.347 & 0.464 & $0.118 * *$ \\
\hline Spouse/partner income $(€)$ & 21873 & 23605 & 20321 & $-3.284 * *$ \\
\hline \multicolumn{5}{|l|}{ Human capital } \\
\hline$\leq$ Primary education & 0.208 & 0.091 & 0.313 & $0.223 * *$ \\
\hline Lower secondary education & 0.353 & 0.290 & 0.409 & $0.120 * *$ \\
\hline Upper secondary education & 0.346 & 0.444 & 0.258 & $-0.186 * *$ \\
\hline Tertiary education & 0.093 & 0.175 & 0.019 & $-0.157 * *$ \\
\hline Age & 42.2 & 41.7 & 42.7 & $1.024 *$ \\
\hline \multicolumn{5}{|l|}{ Family and cultural background } \\
\hline Working mother & 0.279 & 0.345 & 0.220 & $-0.126 * *$ \\
\hline Working mother-in-law & 0.250 & 0.320 & 0.187 & $-0.133 * *$ \\
\hline Centre-North & 0.630 & 0.776 & 0.499 & $-0.276 * *$ \\
\hline South & 0.370 & 0.224 & 0.501 & $0.276^{* *}$ \\
\hline Number of observations & 1519 & 718 & 801 & \\
\hline
\end{tabular}

Note: $* p<.1 ; * * p<.05$

education and more than half have less than upper secondary education. However, participating women possess a considerably higher education level than non-participating women; $62 \%$ of participating women has at least upper secondary education level while this is the case for only $27.7 \%$ of non-participating women; only $1.9 \%$ of non-participating women possess tertiary education versus $17.5 \%$ of participating women. A large fraction of non-participating women $(31.3 \%)$ has an education level less than or equal to primary education. The mean age is around 42 in both sub-samples.

The mean spouse/partner's income is higher for participating women; this fact may be due to assortative mating, i.e., likes marry likes. In particular, female participation in Italy is considerably higher for more educated women. Since highly educated people are more likely to marry someone with a similar education, we expected that participating women are more often married to better educated men, who, on average, earn higher wages. Analysing data from the Bank of Italy's 1995 Survey of Household Income and Wealth, Del Boca et al. (2000) and Rossetti and Tanda (2000) reported strong evidence of assortative mating for Italian couples.

In the sub-sample of participating women, the percentages of those with a working mother/mother-in-law at the woman's present age are significantly higher than the same 
Table 2 Women demanding informal help

\begin{tabular}{llll}
\hline & $\begin{array}{l}\text { Participating } \\
\text { women }\end{array}$ & $\begin{array}{l}\text { Non-participating } \\
\text { women }\end{array}$ & Total \\
\hline Whole sample & .162 & .041 & .098 \\
Age of the youngest child & & & \\
$\quad$ 0-2 years old & .407 & .146 & .268 \\
3-5 years old & .283 & .076 & .183 \\
6-10 years old & .207 & .042 & .131 \\
11-14 years old & .087 & .022 & .058 \\
Above 14 years old & .028 & .008 & .016 \\
\hline
\end{tabular}

percentages calculated on the sub-sample of non-participating women. Finally, descriptive analysis points out huge geographical differences in the participation pattern of Italian women: Southern women make up $37 \%$ of the estimation sample, but the percentage decreases to $22.4 \%$ in the sub-sample of participating women, and it is more than $50 \%$ in the sub-sample of non-participating women.

In order to further investigate the relationship between participation and family connections, Table 2 displays the percentage of women receiving informal help separately for participating and non-participating women; the percentages are computed separately also by age of the youngest child. As it can be seen from the table, participating women turn more frequently to informal help and the percentage of women demanding support from the enlarged family grows as the age of the youngest child decreases. In particular, among participating women those with pre-school children recur considerably more than other women to informal help.

\section{Regression Results}

In this section we present estimates of the effect of family connections in explaining the choice to be in the labor force. Estimations were conducted on a sample of 1,519 married/ partnered mothers. Simulated maximum likelihood estimates of the parameters of the trivariate probit model are given in Table 3 (participation equation), in Table 6 (help received equation) and in Table 7 (care provided equation).

To facilitate inference on the quantitative effect of the categorical regressors on participation, we computed the changes in predicted participation probability as dummies for family connections and other model's dummy variables change from zero to one, keeping other controls fixed at their sample means (see Table 4). The table shows that the participation probability predicted using real data is $47.3 \%$, which is equal to the participation rate calculated on the estimation sample and similar to the Italian participation rate, which in 2001 was $48 \%$.

\section{Participation Equation}

Almost all the participation equation coefficients are significantly different from zero and they have the expected sign; recall that a positive/negative sign of the coefficient implies a positive/negative impact of the regressor on the probability of labor market participation. The results confirm a strong influence of both help received and care provided on female 
Table 3 Trivariate probit: participation equation $(n=1,519)$

\begin{tabular}{|c|c|c|}
\hline & $\beta$ & SE \\
\hline \multicolumn{3}{|l|}{ Family links } \\
\hline Help received & $0.687^{* *}$ & 0.263 \\
\hline Care provided & $-0.286^{* * *}$ & 0.165 \\
\hline Youngest child $3-5$ years old & 0.234 & 0.148 \\
\hline Youngest child 6-10 years old & $0.288 *$ & 0.146 \\
\hline Youngest child $11-14$ years old & $0.413 *$ & 0.169 \\
\hline Youngest child over 14 & $0.352 *$ & 0.172 \\
\hline Places in public senior care facilities $/ 100$ & $0.004 * * *$ & 0.003 \\
\hline Places in kindergartens $/ 100$ & $0.031^{*}$ & 0.015 \\
\hline Spouse/partner income (thousand $€$ ) & $-0.018 * *$ & 0.005 \\
\hline Squared spouse/partner income & $0.000 *$ & 0.000 \\
\hline \multicolumn{3}{|l|}{ Human capital } \\
\hline$\leq$ Primary education & $-1.989 * *$ & 0.183 \\
\hline Compulsory education & $-1.552 * *$ & 0.167 \\
\hline Secondary education & $-0.954 * *$ & 0.162 \\
\hline Age & $0.135^{* *}$ & 0.042 \\
\hline Squared age & $-0.002 * *$ & 0.000 \\
\hline \multicolumn{3}{|l|}{ Family, cultural and economic background } \\
\hline Working mother & $0.143 * * *$ & 0.083 \\
\hline Working mother-in-law & $0.217 *$ & 0.087 \\
\hline South & -0.171 & 0.211 \\
\hline Regional unemployment rate & $-0.010 * * *$ & 0.006 \\
\hline Constant & $-1.669 * * *$ & 0.940 \\
\hline$\rho_{P H}$ & -0.024 & 0.123 \\
\hline$\rho_{P C}$ & 0.111 & 0.114 \\
\hline \multicolumn{3}{|l|}{ Prob $>\chi^{2}=.000$} \\
\hline Log likelihood $=-2051.680$ & & \\
\hline
\end{tabular}

participation, in accordance with the predictions of the household production model described in section "Family Ties and Participation" and with descriptive analysis depicted in Table 1.

First of all, the coefficient relative to $H$ (help received dummy variable) is positive and highly significant, confirming that the probability of market work is higher for women that receive informal help from the extended family. Table 4 shows that if the woman receives help from older relatives her probability to participate increases by around $41 \%$; thus, the effect of the original family's support in caring for children and performing household tasks is fundamental in increasing Italian women's probability of being in the labor market.

In order to further analyze the role of caregiving older relatives on female labor market participation, we computed the change in predicted participation probability as the dummy for help received changes from zero to one, keeping other controls fixed at their sample means. This change was computed for women with different levels of education and with the youngest child in different age-ranks. This computation provides a measure of the impact of receiving help on participation for different kinds of women. Results are reported in Table 5. This latter indicates that the role of older relatives in favoring participation is 
Table 4 Effect of explanatory variables on participation
Note: ${ }^{a}$ Percentage change in participation probability with respect to actual probability

Table 5 Effect of help received

\begin{tabular}{llc}
\hline & Probability & $\%$ change $^{\mathrm{a}}$ \\
\hline Predicted participation probability & 0.473 & \\
Simulated participation probability & & \\
Family links & & \\
$\quad$ Help received & 0.668 & 41.3 \\
Care provided & 0.407 & -13.9 \\
Youngest child 0-2 years old & 0.383 & -19.0 \\
Youngest child 3-5 years old & 0.432 & -8.7 \\
Youngest child 6-10 years old & 0.462 & -2.3 \\
Youngest child 11-14 years old & 0.493 & 4.2 \\
$\quad$ Youngest child over 14 & 0.464 & -1.9 \\
Human capital & & \\
$\quad$ Primary education & 0.247 & -47.7 \\
Compulsory education & 0.385 & -18.6 \\
Secondary education & 0.595 & 26.0 \\
$\quad$ Tertiary education & 0.863 & 82.6 \\
Family and cultural background & & \\
$\quad$ Working mother & 0.505 & 6.8 \\
$\quad$ Working mother-in-law & 0.523 & 10.8 \\
$\quad$ South & 0.437 & -7.5 \\
\hline
\end{tabular}

Simulated participation probability

Help received Help not received

$\begin{array}{lll}\text { Family links } & & \\ \text { Youngest child 0-2 years old } & 0.601 & 0.364 \\ \text { Youngest child 3-5 years old } & 0.672 & 0.413 \\ \text { Youngest child 6-10 years old } & 0.687 & 0.447 \\ \text { Youngest child 11-14 years old } & 0.722 & 0.473 \\ \quad \text { Youngest child over 14 } & 0.661 & 0.444 \\ \begin{array}{l}\text { Human capital } \\ \quad \text { Primary education }\end{array} & 0.448 & 0.224 \\ \text { Compulsory education } & 0.606 & 0.360 \\ \text { Secondary education } & 0.791 & 0.574 \\ \text { Tertiary education } & 0.953 & 0.854\end{array}$

especially important for women with very young children, for whom the opportunity cost of market work is particularly high if they have to pay for formal child-care. For example, for women with the youngest child in the 0-2 age rank, the participation probability decreases by $36 \%$ if they do not receive help from relatives, while the same probability decreases by $29 \%$ if the youngest child is between 11 and 14 . The effect of help received monotonically decreases with the level of education, and it is very high for women with 
primary education. An explanation for this result is the lower market wage (and, thus, the lower opportunity cost of time not spent on the market) for less educated women who, more frequently than more educated women, decide to participate in the labor market only when receiving free of charge informal help from the extended family.

On the whole, results shown in Table 5 suggest that the help supplied by older relatives is important especially for enhancing labor market participation of women with a high/low opportunity cost of market/house work, i.e., of less educated women with very young children. These are also the types of women for whom we observed a particularly low participation rate.

As to the impact of other family connections, estimation results indicate that if women dedicate time to caring for a senior member of the enlarged family, their probability of being employed or searching for a job decreases: For married/partnered mothers who care for older relatives, the probability to participate decreases by around $14 \%$ (see Table 4). Hence, the importance of caring for seniors in determining women's attitude towards work on the market adds to the need to care for children and to carry out household chores, further discouraging participation in the labor market. The offer of public care facilities at a regional level relieves the burden of caring for older relatives and favors labor market attachment, as demonstrated by its positive and significant coefficient.

The presence and young age of children has a strong negative impact, which is consistent with theoretical expectations and with several empirical analyses conducted on Italian data (among others, Addabbo 1999; Chiuri 2000). The presence of a child between 0 and 2 years old strongly discourages participation compared to the presence of children in other age groups, with the exception of the presence of 3- to 5-year-old children; notice also that the discouraging effect of children diminishes as they grow older until 14 years old. The offer at the regional level of formal child-care services favors female participation. Evidence for Italy of the positive effect of the availability of child-care services emerges among others from studies by Bratti (2003), Chiuri (2000) and Del Boca (1997, 2002).

Labor supply decreases with the income of the husband/partner due to a negative income effect. Turning to human capital regressors, our results are in line with theoretical expectations and with the findings of several previous empirical analyses (for Italy, among others see Addabbo 1999; Bettio and Villa 1999; Bratti 2003; Chiuri 2000; Tanda 1994): participation monotonically increases with the education level, which on the whole turns out to be the most important determinant of female participation. With respect to actual probability, the participation probability of women with primary education was $47.7 \%$ lower, while the participation probability of women with tertiary education was $82.6 \%$ higher (see Table 4).

Participation probability grows until 39 years of age and decreases rapidly in later years. Family, cultural and economic background are important determinants of female propensity to market work: The fact that women from the previous generation worked for the market favors female participation and it is interesting to observe that the influence of the mother-in-law proves to be greater than the mother's, indicating a strong transmission of the husband's cultural model.

The coefficient of the regional unemployment rate is negative and statistically significant, indicating that participation rate is lower where the labor market performs poorly, as in the South of Italy. Residence in the South, after controlling for regional unemployment rate, does not reduce participation probability. These two latter results suggest that the behavior of Southern women is more linked to the negative performance of the labor market than to a cultural effect. Indeed, as mentioned above, the higher unemployment rate 
and the larger incidence of long-term unemployment in the South compared to elsewhere in the country contributes to increasing the number of discouraged workers, inactive because they think that it is not possible to find a job.

\section{Help Received and Care Provided Equations}

As emerges from Table 6, women with young children are more likely to receive help from the previous generation; recalling that the excluded category are women with the youngest child in the 0-2 age-rank, the probability of receiving help decreases monotonically with the age of the youngest child, pointing to the importance of family help especially for informal care-services of very young children.

The negative sign of the coefficient of the variable describing the number of places in public senior care facilities at a regional level suggests that when women can rely on public formal elder-care services, they can devote more time to child-care and other family responsibilities and thus they need less help from extended family. A negative sign was also found for the variable measuring the number of places in kindergartens, pointing to a substitution effect between formal and informal childcare. However, the coefficient is not

Table 6 Trivariate probit: help received $(n=1,519)$

\begin{tabular}{|c|c|c|c|}
\hline \multirow{2}{*}{$\begin{array}{l}\text { Table } 6 \text { Trivariate probit: help } \\
\text { received }(n=1,519)\end{array}$} & & $\beta$ & SE \\
\hline & \multicolumn{3}{|l|}{ Family links } \\
\hline & Youngest child 3-5 years old & $-0.259 * * *$ & 0.154 \\
\hline & Youngest child 6-10 years old & $-0.383^{*}$ & 0.157 \\
\hline & Youngest child 11-14 years old & $-0.645^{* *}$ & 0.210 \\
\hline & Youngest child over 14 & $-0.975^{* *}$ & 0.240 \\
\hline & Places in public senior care facilities $/ 100$ & $-0.025^{*}$ & 0.010 \\
\hline & Places in kindergartens/100 & -0.014 & 0.021 \\
\hline & Spouse/partner income (thousand $€$ ) & -0.032 & 0.066 \\
\hline & Squared spouse/partner income & 0.000 & 0.001 \\
\hline & \multicolumn{3}{|l|}{ Human capital } \\
\hline & $\leq$ Primary education & $-0.824 * *$ & 0.242 \\
\hline & Compulsory education & $-0.755^{* *}$ & 0.173 \\
\hline & Secondary education & $-0.613^{* *}$ & 0.160 \\
\hline & Age & 0.080 & 0.073 \\
\hline & Squared age & -0.002 & 0.001 \\
\hline & \multicolumn{3}{|l|}{ Family, cultural and economic background } \\
\hline & Working mother & 0.055 & 0.114 \\
\hline & Working mother-in-law & -0.060 & 0.118 \\
\hline & South & -0.254 & 0.304 \\
\hline & Regional unemployment rate & -0.025 & 0.016 \\
\hline & Town $£ 50,000$ inhabitants & $0.252^{*}$ & 0.105 \\
\hline & Constant & -0.731 & 1.454 \\
\hline & $\rho_{H P}$ & -0.024 & 0.123 \\
\hline & $\rho_{H C}$ & $0.074 * * *$ & 0.044 \\
\hline & \multicolumn{3}{|l|}{ Prob $>\chi^{2}=.000$} \\
\hline $\begin{array}{l}\text { Note: } * p<.1 ; * * p<.05 \\
* * * p<01\end{array}$ & \multicolumn{3}{|l|}{ Log likelihood $=-2051.680$} \\
\hline
\end{tabular}

Note: $* p<.1$; ** $p<.05$; $* * * p<.01$ 
statistically significant. A negative relationship between formal childcare and co-residence with grandmothers was found in Joesch (1998) in a study based on U.S. data. Finally, less educated women are less likely to demand family help.

The outcome of the test (test 2) on the significance of the instrument in the help received equation (residence in town with less than 50,000 inhabitants) indicates that the null hypothesis of non-significance is rejected, supporting the validity of this instrument. The positive sign of the coefficient reveals that, as expected, the probability of demanding informal family help is higher for women living in smaller towns.

Considering the care provided equation, the results reported in Table 7 show that, after controlling for woman's age, the highest probability of care-providing among mothers was for those with the youngest child older than 14. From estimation emerges also substitutability between public formal and family informal elderly care services: Results show that the provision of care services by women decreases with the availability of places in public senior care facilities.

Even in this case the outcome of the test (test 2) on the significance of the instruments supports their validity. The estimated coefficients indicated that as the age of the oldest parent/parent-in-law grows, so does the probability of caregiving, and that the same probability decreases with the woman's number of sisters, bearing out that daughters tend to split care services among themselves.

The last two rows of Tables 3, 6 and 7 show the estimated correlation coefficients $\rho_{i j}$ $(i, j=P, H, C ; i \neq j$ ) and their standard errors. After accounting for the impact of observable characteristics, we see that in one case the null hypothesis of absence of bias can be rejected. In particular, the positive sign of $\rho_{H C}$ suggests that there is a positive correlation between the probability to receive informal help and to provide care-services. This correlation is likely to be induced by unobservable personal characteristics such as a stronger relationship with the family of origin, which makes the solidarity pact between generations stronger. The negative sign of $\rho_{P H}$ suggests that women participating for reasons that the model does not capture are less likely to receive informal help, while the positive sign of $\rho_{P C}$ indicates that unobservable characteristics have similar effects on market and household work. However, the coefficients of these latter correlations are not statistically different from zero. Finally, the $t$ tests conducted (test 1 ) indicate that the instruments $Z_{1}$ and $Z_{2}$ do not influence participation in a statistically significant way. ${ }^{4}$

\section{Conclusion}

In this paper we thoroughly analyzed the link between work choices of women and crossgenerational family ties in Italy. A rapid demographic change is under way in western countries, due to low fertility rates and to a longer average life span. According to forecasts, in Italy by the year 2020 the dependency index of older people, calculated as the ratio between the population over 64 and the working age population (ages 15-64), will be above $30 \%$ (Visco 2000). Besides the problems related to the sustainability of the pension system, this implies an increase in the demand for care by seniors which, according to the

\footnotetext{
4 The coefficient of the dummy variable for residence in a city with less than 50,000 inhabitants $\left(Z_{1}\right)$ was 0.003 , and the standard error was 0.074; the coefficients/standard errors of the variables number of sisters of the woman and age of the oldest relative among parents and parents-in-law (vector $Z_{2}$ ) were, respectively, $-0.044 / 0.031$ and $-0.001 / 0.002$. Thus, these variables were not statistically significant, and this fact ensures the validity of the used exclusion restrictions.
} 
Table 7 Trivariate probit: care provided equation $(n=1,519)$

\begin{tabular}{|c|c|c|c|}
\hline \multirow{2}{*}{$\begin{array}{l}\text { Table } 7 \text { Trivariate probit: care } \\
\text { provided equation }(n=1,519)\end{array}$} & & $\beta$ & $\mathrm{SE}$ \\
\hline & \multicolumn{3}{|l|}{ Family links } \\
\hline & Youngest child 3-5 years old & 0.174 & 0.151 \\
\hline & Youngest child $6-10$ years old & 0.208 & 0.148 \\
\hline & Youngest child $11-14$ years old & 0.168 & 0.170 \\
\hline & Youngest child over 14 & $0.378^{*}$ & 0.169 \\
\hline & Places in public senior care facilities/100 & $-0.023^{* *}$ & 0.007 \\
\hline & Places in kindergartens $/ 100$ & -0.025 & 0.019 \\
\hline & Spouse/partner income (thousand $€$ ) & 0.005 & 0.005 \\
\hline & Squared spouse/partner income & -0.000 & 0.000 \\
\hline & \multicolumn{3}{|l|}{ Human capital } \\
\hline & $\leq$ Primary education & 0.101 & 0.154 \\
\hline & Compulsory education & 0.143 & 0.139 \\
\hline & Secondary education & -0.018 & 0.135 \\
\hline & Age & 0.037 & 0.042 \\
\hline & Squared age & 0.000 & 0.000 \\
\hline & \multicolumn{3}{|l|}{ Family, cultural and economic background } \\
\hline & Working mother & -0.020 & 0.085 \\
\hline & Working mother-in-law & $-0.167 * * *$ & 0.089 \\
\hline & South & 0.201 & 0.205 \\
\hline & Regional unemployment rate & -0.010 & 0.010 \\
\hline & Age of the oldest parent/parent-in-law & $0.004 *$ & 0.002 \\
\hline & Number of sisters & $-0.061^{*}$ & 0.030 \\
\hline & Constant & -1.510 & 0.938 \\
\hline & $\rho_{C P}$ & 0.111 & 0.114 \\
\hline & $\rho_{C H}$ & $0.074 * * *$ & 0.044 \\
\hline & \multicolumn{3}{|l|}{ Prob $>\chi^{2}=.000$} \\
\hline $\begin{array}{l}\text { Note: } * p<.1 ; * * p<.05 \\
* * * p<.01\end{array}$ & \multicolumn{3}{|l|}{ Log likelihood $=-2051.680$} \\
\hline
\end{tabular}

Note: $* p<.1 ; * * p<.05$; $* * * p<.01$

traditional division of roles within the family, is largely met by women: In 1998, in Italy $24.5 \%$ of women provided free support to non-co-residing people, $26 \%$ of them to non-coresiding older persons (Istat 2001). One must add to these women those who provide assistance to seniors residing within the family nucleus. The responsibilities toward seniors-added to those toward children - has led to the definition of the term sandwich generation with reference to women who need to provide care both to the preceding and to the following generation. An increase in care obligations could discourage the presence of women in the labor market, which is already particularly low in Italy, where the participation and employment rates in 2001 were $48 \%$ and $42 \%$, respectively, versus a European Union average of $61 \%$ and $55 \%$.

However, cross-generational solidarity may also operate the other way around, since women may receive help from the previous generation in dealing with household chores and caring for family members; this fact may play an important role in favoring their participation decision. To capture the different impacts of older relatives, we estimated a trivariate probit model assuming that the three choices of being in the labor force, of receiving and of providing informal family support are jointly determined. After controlling for a wide range of variables, our empirical results indicate that women receiving 
informal family help are characterized by a remarkably higher probability of being in the labor market. This effect is especially strong for women with a very low education level and with very young children, who are also the female group characterized by the lowest participation rate.

The effect of the commitment to care for older relatives is negative although quantitatively rather small. The results also shown a positive impact of both child and senior institutional care services.

From the policy maker point of view, the huge increase in the probability of participation induced by the presence of informal help suggests the importance of the availability of care services at a low cost and with high flexibility, like those provided by older parents. With respect to the Italian child care services, for example, the low coverage, high cost and rigidity of opening hours mean that the existing public services do not provide much assistance in combining household work with work on the market (Del Boca 2002). Our results suggest that an increase in Italian female participation rate could be obtained through policies for the family both toward children and older relatives, thereby reducing the burden of family responsibilities for women.

\section{References}

Addabbo, T. (1999). Labor supply and employment probabilities in Italy: A gender analysis in a regional perspective. Economia e Lavoro, 33, 189-207.

Banca D'Italia. (2002). I bilanci delle famiglie italiane nell'anno 2000. Supplemento al Bollettino Statistico. Note metodologiche e Informazioni Statistiche. Roma: Banca d'Italia.

Becker, G. S. (1965). A theory of the allocation of time. Economic Journal, 7, 493-517.

Bettio, F., \& Villa, P. (1999). To what extent does it pay to be better educated? Education and market work for women in Italy. South European Society and Politics, 4, 150-171.

Bratti, M. (2003). Female labor force participation and marital fertility of Italian women: The role of education. Journal of Population Economics, 16, 525-554.

Browning, M. (1992). Children and household economic behavior. Journal of Economic Literature, 30, $1434-1475$.

Bryant, K. W. (1990). Work and leisure: How the household spends its time. In The economic organization of the household (pp. 125-197). New York: Cambridge University Press.

Cappellari, L., \& Jenkins, P. S. (2003). Multivariate probit regression using simulated maximum likelihood. The Stata Journal, 3, 221-222.

Caputo, R. K. (2002). Adult daughters as parental caregivers: Rational actors versus rational agents. Journal of Family and Economic Issues, 23, 27-50.

Chang, C., \& White-Means, S. I. (1995). Labor supply of informal care-givers. International Review of Applied Economics, 9, 192-205.

Chiuri, M. C. (2000). Quality and demand of child care and female labor supply in Italy. Labour, 14, 97-118.

Del Boca, D. (1997). Intrahousehold distribution of resources and labor market participation decisions. In I. Persson \& C. Jonung (Eds.), Economics of the family and family policies (pp. 65-83). London: Routledge Press.

Del Boca, D. (2002). The effect of child care and part time opportunities on participation and fertility decisions in Italy. Journal of Population Economics, 15, 549-573.

Del Boca, D., Locatelli, M., \& Pasqua, S. (2000). Employment decisions of married women: Evidence and explanation. Labour, 14, 35-52.

Ettner, L. S. (1995). The impact of "parent care" on female labor supply decisions. Demography, 32, 63-80.

Ettner, L. S. (1996). The opportunity cost of elder care. Journal of Human Resources, 31, 189-205.

Greene, W. H. (2003). Econometric analysis (5th ed., pp. 931-933). Upper Saddle River, NJ: Prentice-Hall.

Hill, E. J., Märtinson, V. K., Ferris, M., \& Zenger Baker, R. (2004). Beyond the mommy track: The influence of new-concept part-time work for professional women on work and family. Journal of Family and Economic Issues, 25, 121-136.

Hunts, H. J. H., \& Avery, R. J. (1998). Relatives as child care givers: After hours support for nontraditional workers. Journal of Family and Economic Issues, 19, 315-341. 
Istat. (2001). Parentela e reti di solidarietà. Indagine Multiscopo sulle famiglie. Aspetti della vita quotidiana: anno 1998 [Kin and solidarity networks. Family survey. Aspects of everyday life: Year 1998]. Roma: Istat.

Joesch, J. M. (1998). Where are the children? Extent and determinants of preschoolers' child care time. Journal of Family and Economic Issues, 19, 75-99.

Koh, S., \& MacDonald, M. (2006). Financial reciprocity and elder care: Interdependent resource transfers. Journal of Family and Economic Issues, 27, 420-436.

Kolodinsky, J., \& Shirey, L. (2000). The impact of living with an elder parent on adult daughter's labor supply and hours of work. Journal of Family and Economic Issues, 21, 149-175.

Lai, D. W. L., \& Leonenko, W. (2007). Effects of caregiving on employment and economic costs of Chinese family caregivers in Canada. Journal of Family and Economic Issues, 28, 411-427.

Meeks, C. B., Nickols, S. Y., \& Sweaney, A. L. (1999). Demographic comparisons of aging in five selected countries. Journal of Family and Economic Issues, 20, 223-250.

Nakamura, A., \& Nakamura, M. (1992). The econometrics of female labor supply and children. Econometric Reviews, 11, 1-71.

Nichols, L. S., \& Junk, V. W. (1997). The sandwich generation: Dependency, proximity, and task assistance needs of parents. Journal of Family and Economic Issues, 18, 299-326.

O'Higgins, N. (1994). YTS, employment, and sample selection bias. Oxford Economic Papers, 46, 605-628.

Presser, H. B. (1989). Some economic complexities of child care provided by grandmothers. Journal of Marriage and the Family, 51, 581-591.

Ribar, D. C. (1992). Child care and labor supply of married women: Reduced form evidence. Journal of Human Resources, 27, 134-165.

Rossetti, S., \& Tanda, P. (2000). Human capital, wages and family interactions. Labour, 14, 5-34.

Tanda, P. (1994). Partecipazione femminile in Italia: evidenza empirica su dati individuali [Female participation in Italy: Empirical evidence on individual data]. Economia e Lavoro, 28, 123-134.

Visco, I. (2000). Welfare, invecchiamento della popolazione e lavoro: una prospettiva OCSE [Welfare, population aging and work: An OECD prospect]. Moneta e Credito, 209, 55-85.

Wolf, D. A., \& Soldo, B. J. (1994). Married women's allocation of time to employment and care of elderly parents. Journal of Human Resources, 29, 1259-1276. 
Copyright of Journal of Family \& Economic Issues is the property of Springer Science \& Business Media B.V. and its content may not be copied or emailed to multiple sites or posted to a listserv without the copyright holder's express written permission. However, users may print, download, or email articles for individual use. 